\title{
CATASTROPHIC SHIFT OF OBESITY IN THREE ZONES OF SUB-HIMALAYAN REGION, INDIA, AND ITS CORELATION WITH THE DIETARY INTAKE
}

\author{
VINITA THAPLIYAL ${ }^{1}$, KARUNA SINGH ${ }^{2}$, ANIL JOSHI ${ }^{3}$
}

${ }^{1}$ Research Scholar, Amity Institute of Food Technology, Amity University, Noida, Uttar Pradesh, India. ${ }^{2}$ Assistant Professor-III, Amity Institute of Food Technology, Amity University, Noida, Uttar Pradesh, India. ${ }^{3}$ (Padam Shree) Director, Himalayan Environmental Studies and Conservation Organization, Dehradun, Uttarakhand, India. Email: Vinita.thapliyal22@gmail.com

Received: 17 January 2018, Revised and Accepted: 14 March 2018

ABSTRACT

Objective: The objective is to study the prevalence of obesity and overweight in three zones of sub-Himalayan Region and its corelation with the dietary intake.

Methods: A survey was conducted in three zones of Uttrakhand (Dehradun, Rudraprayag, and Uttarkashi), India, representing the urban, semi-urban, and rural village population (18-45 years) of the state. For the study, 100 adults were selected from each of the 3 zones, respectively, to make a total sample size of 300 adults using purposive random sampling.

Results: The high prevalence obesity and overweight occur among urban zone (Dehradun), followed by semi-urban zone, Rudraprayag, district of Uttrakhand. In Dehradun, $6.1 \%$ of males and $29.4 \%$ of females were obese, whereas $62.1 \%$ males and $58.8 \%$ of females were overweight. In Rudraprayag, $13.6 \%$ of males and $14.6 \%$ of females were obese, whereas $35.6 \%$ of males and $39 \%$ of females were overweight. In rural zone (Uttarkashi), there were no cases of obesity among both males and females.

Conclusion: A high prevalence rate of obesity was depicted in the urban zone of Uttrakhand region. Urbanization seems to have a positive significant impact on the prevalence of obesity with women being at greater risk.

Keywords: Obesity, Overweight, Uttrakhand

(C) 2018 The Authors. Published by Innovare Academic Sciences Pvt Ltd. This is an open access article under the CC BY license (http://creativecommons. org/licenses/by/4. 0/) DOI: http://dx.doi.org/10.22159/ajpcr.2018.v11i4.24798

\section{INTRODUCTION}

Obesity is a global epidemic health crisis as around $10 \%$ of populations worldwide are overweight and $25 \%$ are obese $[1,2]$. The prevalence of overweight and obesity ranges between 9 and $27 \%$ and 1 and $12.9 \%$, respectively, in India [3].

The excess of body fat that has accumulated to an extent that health is adversely affected is defined as obesity 1. Body mass index (BMI) is widely used to estimate the prevalence of overweight and obesity within a population, and it is calculated as weight $(\mathrm{kg}) /$ height squared $\left(\mathrm{m}^{2}\right)$. The previous studies have shown that BMI is positively correlated with total body fat for the significant population [1]. The health concerns with obesity arise as it has been found to be a significant contributing factor to serious diseases including cardiovascular disease, Type 2 diabetes, and hypertension [2], and the swift increase in prevalence worldwide over the past decades would also cause for the increase in prevalence of obesity-related degenerative diseases. Overweight and obesity have been shown to be related to multiple chronic degenerative problems and lead to a heavy economic burden on families and increasing costs to society throughout the world [4-6]

As per the World Health Organization (WHO) report Flegal et al. [7], obesity is body mass index (BMI) $\geq 30 \mathrm{~kg} / \mathrm{m}^{2}$, and over- weight as a BMI of $25-29.9 \mathrm{~kg} / \mathrm{m}^{2}$. For Asian and Indian population, obesity suggests a $\mathrm{BMI} \geq 25 \mathrm{~kg} / \mathrm{m}^{2}$ and overweight indicates a BMI of more than $23 \mathrm{~kg} / \mathrm{m}^{2}$ [5]. By the American Medical Association in 2013 so that physician pays more attention to the problem, obesity is classified as a disease $[8,9]$. Multifactorial elements result in this outbreak with the environmental, urbanization, and behavioral interactions declared to contribute a major role in the development of obesity [10].

As per the WHO, obesity is one of the most common, yet among the most neglected, public health problems in both developed and developing countries [11]. Globally, one in six adults is obese and nearly 2.8 million individuals die each year due to overweight or obesity as per the WHO, World Health Statistics Report 2012 [12,13].

Obesity is now being recognized as a disease in its own right due to high risk of morbidity and mortality. Degenerative disorders including diabetes, hypertension, dyslipidemia, cardiovascular disease, and even some cancers are strongly associated with obesity. The risk for these diseases seems to appear [14] from a BMI of about 21 $\mathrm{kg} / \mathrm{m}^{2}$. Obesity is generally classified as abdominal obesity and generalized obesity. The risk rates of mortality and morbidity are high among obese individuals as compared to non-obese individuals [15]. India, with 1.2 billion people, is the second most populous country in the world and currently is in a state of rapid epidemiological transition. Undernutrition which dominated in the past is being rapidly replaced by obesity associated with affluence [16]. Globalization, industrialization and urbanization also play a significant role to increase the prevalence of obesity. Various studies from different parts of India have provided facts of the increasing prevalence of obesity [16-19]. Although most reports have been region and area specific (mostly from urban areas),different studies have used different research methodologies,

definitions, and cutoff points for defining obesity, making the process of comparisons difficult. Till date, there has been no study on the prevalence of obesity in India that can be a national representative. METHODS

\section{Data collection}

The data were collected using the WHO STEPS questionnaire approach. Interview technique was used by the investigator herself after ensuring the confidentiality of the information. After filling the questionnaire, the respondents were called to a separate room for anthropometric measurements and variables such as weight (kilograms) using Karda digital weighing scale, height (centimeters) using stadia meter, BMI $\left(\mathrm{kg} / \mathrm{m}^{2}\right)$, and WC (waist circumference in centimeters) were recorded using standard procedures. 
The modified classification of BMI for Asian populations was used in this study to define overweight $\left(23-24.99 \mathrm{~kg} / \mathrm{m}^{2}\right)$ and obesity $\left(>25 \mathrm{~kg} / \mathrm{m}^{2}\right)$. Cutoff points used to define central obesity were waist-hip ratio $>0.90$ in men and $>0.80$ in women was taken as high. 18 body Fat $\%$ $>25 \%$ in males and $>30 \%$ in females was taken as high $[8,9]$.

Analysis was carried out using SPSS version 17.0. Pearson's Chi-square test was used to evaluate differences between groups for categorized variables. Normally distributed data were $90 \%$ confidence intervals.

\section{Sample size}

The sample size calculated was 269 with a confidence interval of $90 \%$ and margin of error 5\%. The calculated sample size was 269, but a sample of 300 participants was included for the study. Written consent was received from every subject.

\section{Data analysis}

The analysis of data was performed using SPSS 17 computer statistical software package. Cross-tabulation and frequency distribution were done to find the relationship with categorical variables. The test used was Chi-square and level of significance $p$ was $0.05(p<0.05)$

\section{RESULTS}

For the study, 300 adults were selected, 100 from each 3 zones (Dehradun, Rudraprayag, and Uttarkashi). The overall response of the study was $100 \%$. Of the 300 adults, $176(58.7 \%)$ were males, whereas $124(41.3 \%)$ were females. The mean age of males from Dehradun, Rudraprayag, and Uttarkashi was $31.5 \pm 8.1,36.9 \pm 8.7$, and 33.1 \pm 9.1 , respectively, whereas, the mean age of females from Dehradun,

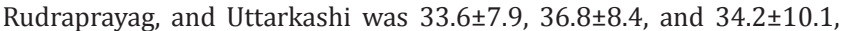
respectively. The literacy level of the population was $96 \%$, whereas $4 \%$ population has never attended school. The mean year of schooling was least in Uttarkashi zone $(\mathrm{p}<0.001)$.

Anthropometric characteristics of males and females when classified according to three zones males from Dehradun had significantly higher weight and BMI as compared to males from Rudraprayag and Uttarkashi $(\mathrm{p}<0.05)$. There was no significant difference in weight and BMI of males from Rudraprayag and Uttarkashi ( $p>0.05$ ). There was no significant difference in the waist circumference of the males from 3 zones $(p>0.05)$. Females from Dehradun had significantly higher weight, BMI, and waist circumference as compared to females from Rudraprayag and Uttarkashi $(\mathrm{p}<0.05)$.

Of the 300 adults, 130 (43.4\%) were normal, 142 (47.3\%) were overweight, and $28(9.3 \%)$ were obese. There was no significant association between BMI status and gender, i.e. there is no difference in the percentage of normal, overweight, and obese between males and females $\left(\chi^{2}=3.912, p=0.203\right)$.

In males, there was a significant association of BMI status and zone with a higher percentage of overweight and obese being from Dehradun followed by Rudraprayag and finally Uttarkashi $\left(\chi^{2}=15.750, p=0.003\right)$. Similarly, in females, there was a significant association of BMI status and zone with a higher percentage of overweight and obese being from Dehradun followed by Rudraprayag and finally Uttarkashi $\left(\chi^{2}=26.597\right.$, p<0.01) (Fig. 1 and Tables 1-3).

Males from Uttarkashi had significantly lesser protein and percentage RDA from protein intake as compared to males from Dehradun and Rudraprayag $(\mathrm{p}<0.05)$ (Table 3). On the other hand, females from Uttarkashi had significantly higher protein and percentage RDA from protein intake as compared to females from Dehradun and Rudraprayag $(\mathrm{p}<0.05)$ (Table 3$)$. Males from Dehradun had significantly higher percentage RDA intake of energy as compared to males from Rudraprayag and Uttarkashi $(p<0.05)$ (Table 3). There was no significant difference in other nutrient intakes of males or females of the 3 zones except the calorie content which is high in Dehradun zone both male and female ( $\mathrm{p}>0.05$ ) (Tables 3 and 4$)$.

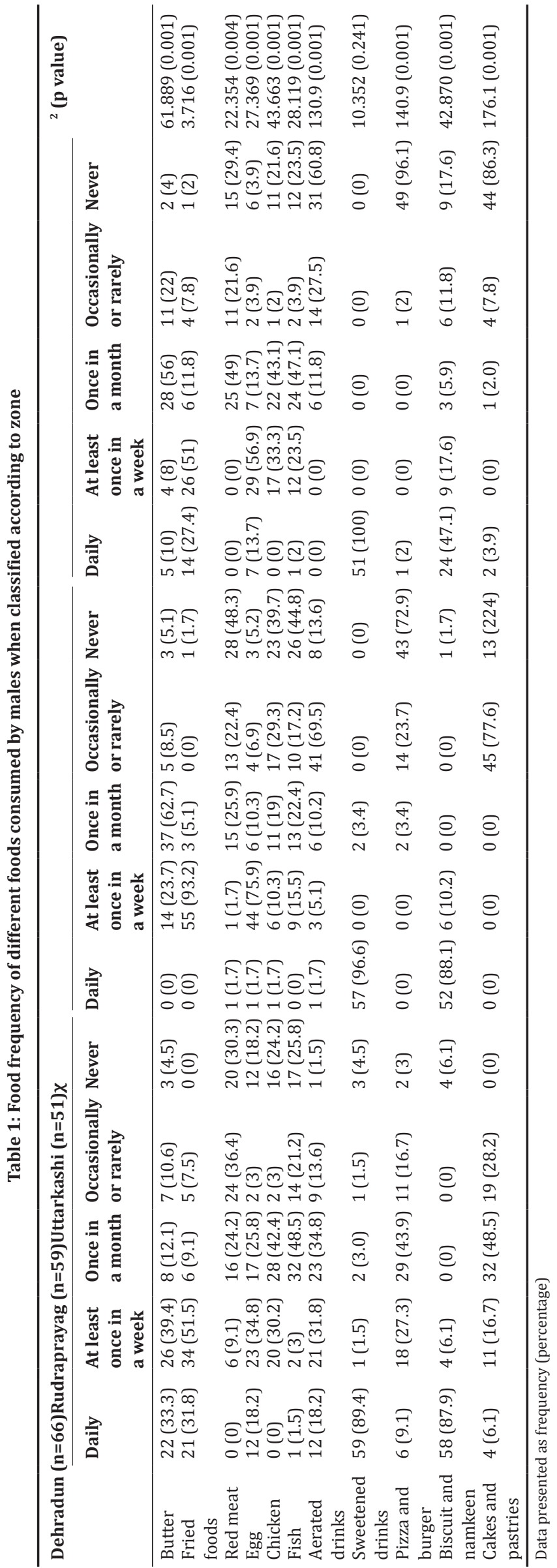


Dietary intake was positively correlated with age, weight, BMI, and waist circumference in Dehradun adults $(\mathrm{p}<0.05)$. There was a significant positive correlation of dietary intake with weight, BMI, and waist circumference in Rudraprayag adults $(p<0.05)$. There was a significant positive correlation of energy and fat intake with weight, BMI, and waist circumference in Uttarkashi adults $(p<0.05)$. There was a significant positive correlation of fat intake with waist circumference in Uttarkashi adults $(p<0.05)$. There was no significant correlation of protein intake with weight, BMI, and waist circumference in Uttarkashi adults $(p>0.05)$. There was no significant correlation of fiber intake with weight and BMI in Uttarkashi adults $(\mathrm{p}<0.05)$. There was no significant correlation of age with dietary intake in Rudraprayag or Uttarkashi adults $(\mathrm{p}>0.05)$

There is no significant difference in the mean calorie intake, but this clearly shows that food preferences as shown in food frequency table have a positive impact on the BMI and waist circumference of the population.

\section{DISCUSSION AND CONCLUSION}

Overall high proportion of respondents was reported to be overweight and obese. Prevalence of obesity increases from rural to urban population with increase being majorly greater for women in comparison with men. Semi-urban population was similar to urban population with regard to the prevalence of obesity and risk factors, indicating total integration of high-risk nutrition transition and urban lifestyle by semi-urban population.

In comparison with men in all three zones, women were worse off except in the rural population. Thus, industrialization and urbanization seem to have a positive significant impact on the prevalence of obesity, NCD, and its associated risk factors, with women being at greater risk. Similar trends for obesity and NCD risk factors from urban to rural population as in our study were reported by Mohan et al. [20]. Data on education of the subjects were gathered and shows that rural population had least education followed by semi-urban and then by urban. Previous studies either report comparison between rural and urban population only or restrict their study to only one gender. A study by Chadha et al. reported a similar differential in BMI in urban-rural population from a survey conducted in Delhi as shown in our study. They also documented

a considerable increase in men-women difference in prevalence of overweight from rural to urban population [21]. Sidhu et al. conducted a survey on a randomized sample of 1700 ( 900 urban and 800 rural) adult Punjabi women in the age group from 20 to 45 years and also reported nearly double overall prevalence rate of overweight/obesity among urban women as compared with rural women $(43.88 \%$ and $22.26 \%$, respectively, for urban and rural women) [22]. A difference of $3 \mathrm{~kg} \mathrm{~m}^{2}$ in mean BMI among rural and urban women was documented by NFHS

2 (1998-1999), Haryana, and was comparable to that reported by our study [23]. A survey conducted by Venkatramana and Reddy on South Indian men reported higher rates of obesity in urban men in comparison with rural men with a difference of $2.5 \mathrm{~kg} \mathrm{~m}^{2}$ in mean BMI [24]. This difference was similar to that documented in our study. Considerable evidence exists that consumption of more energy-dense food and poor consumption of fruits and vegetables increase the risk for degenerative diseases [25,26]. Numerous proposed actions can embrace for promoting quality diet: The allocation of information and education to the people at large, the purveying of information at the point of purchase and food labeling, and the restriction of advertising and of health claims. Public health providers even advocate taxing these snacks, among other price intercession [27]. The NCD outbreak in developing countries is taking place at a swift pace than economically developed countries [28-30]. In a review done in 1996 Gupta et al. reported that the rise in the prevalence of CHD from $1 \%$ in 1960 to $9.6 \%$ in 1995 among urban population and from $2 \%$ to $3.7 \%$ among rural population of India. The prevalence is now (2005) reported to be $3-4 \%$ in rural and $8-10 \%$ in urban population [31] (the WHO report 2005). As per estimation made by the National Commission on Macroeconomics and Health, cardiovascular disease is expected to rise from a level of about 380

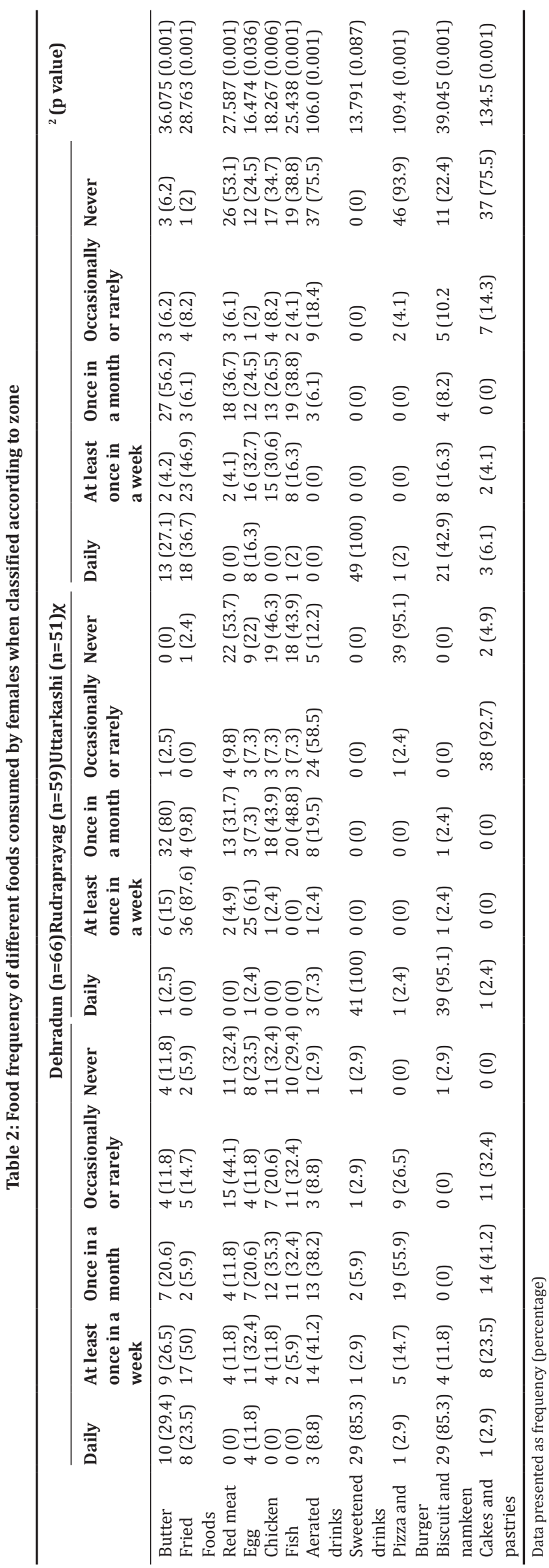


Table 3: Dietary Intake of males and females when classified according to zone

\begin{tabular}{|c|c|c|c|c|c|c|}
\hline & \multicolumn{3}{|l|}{ Males (n=176) } & \multicolumn{3}{|l|}{ Females $(n=124)$} \\
\hline & Dehradun $(n=66)$ & Rudraprayag $(n=59)$ & Uttarkashi $(n=51)$ & Dehradun $(n=34)$ & Rudraprayag $(n=41)$ & Uttarkashi $(n=49)$ \\
\hline Energy (kcal/day) & $2522 \pm 329$ & $2200 \pm 313$ & $2198 \pm 267$ & $2446 \pm 258$ & $2066 \pm 255$ & $2060 \pm 220$ \\
\hline Protein (g/day) & $64.2 \pm 7.2$ & $64.7 \pm 6.6$ & $61.2 \pm 6.2^{\# \$}$ & $58.7 \pm 5.2$ & $59.0 \pm 4.8$ & $62.3 \pm 8.0^{\# \$}$ \\
\hline Fat (mg/day) & $32 \pm 3.3$ & $21.7 \pm 3.1$ & $20.3 \pm 2.6$ & $33 \pm 2.7$ & $22 \pm 2.6$ & $18.3 \pm 2.0$ \\
\hline Fiber (mg/day) & $15.4 \pm 2.8$ & $24.1 \pm 3.4$ & $26.2 \pm 3.6$ & $534.0 \pm 80.5$ & $503.3 \pm 81.2$ & $531.6 \pm 77.9$ \\
\hline
\end{tabular}

${ }^{*} \mathrm{p}<0.05$ for comparison between Dehradun and Rudraprayag. $\# \mathrm{p}<0.05$ for comparison between Dehradun and Uttarkashi. $\$ \mathrm{p}<0.05$ for comparison between Rudraprayag and Uttarkashi

Table 4: Correlation of obesity with dietary intake when classified according to zone

\begin{tabular}{|c|c|c|c|c|c|c|c|c|c|c|c|c|}
\hline & \multicolumn{4}{|c|}{ Dehradun $(n=100)$} & \multicolumn{4}{|c|}{ Rudraprayag (n=100) } & \multicolumn{4}{|c|}{ Uttarkashi $(n=100)$} \\
\hline & Age & Weight & BMI & $\begin{array}{l}\text { Waist } \\
\text { circumference }\end{array}$ & Age & Weight & BMI & $\begin{array}{l}\text { Waist } \\
\text { circumference }\end{array}$ & Age & Weight & BMI & $\begin{array}{l}\text { Waist } \\
\text { circumference }\end{array}$ \\
\hline Energy & $0.401^{*}$ & $0.456^{*}$ & $0.510^{*}$ & $0.453^{*}$ & 0.016 & $0.493^{*}$ & $0.468 *$ & $0.452 *$ & -0.089 & $0.397 *$ & $0.364^{*}$ & $0.301^{*}$ \\
\hline Protein & $0.265^{*}$ & $0.516^{*}$ & $0.307^{*}$ & $0.335^{*}$ & 0.058 & $0.400^{*}$ & $0.264^{*}$ & $0.344^{*}$ & -0.09 & -0.04 & -0.084 & -0.116 \\
\hline Fat & $0.370^{*}$ & $0.492^{*}$ & $0.389 *$ & $0.372^{*}$ & 0.038 & $0.503^{*}$ & $0.341^{*}$ & $0.433^{*}$ & -0.047 & $0.524^{*}$ & $0.308^{*}$ & $0.358^{*}$ \\
\hline Fiber & $0.380^{*}$ & $0.363^{*}$ & $0.417^{*}$ & $0.430^{*}$ & 0.041 & $0.408^{*}$ & $0.340^{*}$ & $0.389 *$ & 0.048 & 0.163 & 0.090 & $0.207^{*}$ \\
\hline
\end{tabular}

Data presented as Pearson correlation value. ${ }^{*} \mathrm{p}<0.05$, BMI: Body mass index

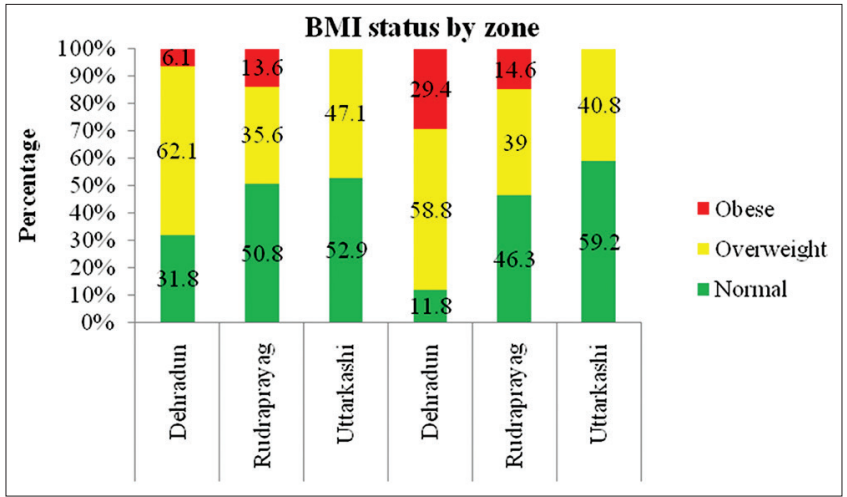

Fig. 1: Percentage of normal, overweight, and obese males and females when classified according to zone

lakh cases in the year 2005 to as many as 641 lakh cases in 2015 [32] Chronic diseases, most of the time, develop through a sequence, starting (in many cases) with behaviors and going through biological risk factors until disease is bring into being. Thus, daunting levels of NCD risk factors outlined in our research portend future increase degenerative incidence in India. A degenerative disease represents a huge and growing share of the disease burden and hence cause for concern, in developing countries around the world. Their potential and known linkages with poverty, the health and economic losses they impose on people, including those of working age, and the demands they will place on resources because of the growing NCD burden associated with lifestyle changes and aging populations are areas of major concern. There is a need for allocation of health system to tackle this increasing burden NCDs, to reduce the health and economic losses among the economically active population, and to prepare for the pressures on health systems, resulting from the growing numbers of people with NCDs associated with epidemiological and demographic changes. Our study has outlined the daunting negative impact of industrialization and urbanization on the prevalence of NCD risk factors. Urbanization and epidemiological transition are major decisive factors of behavior and need to be addressed at the policy, program, and plan levels. As these transitions are unavoidable and are likely to take place at even faster pace in future, lifestyle modifications have to be promoted to offset its negative impact. Moreover, the far major influence on women in comparison with men warrants gender-sensitive policies categorically targeting them. Education, communication, and information activities categorically focusing on urban lifestyle and advocating adoption of healthy lifestyles need to be enforced aggressively.

\section{REFERENCES}

1. Waxman A. Prevention of chronic diseases: WHO global strategy on diet, physical activity and health. Food Nutr Bull 2003;24:281-4.

2. Dietz WH, Robinson TN. Clinical practice. Overweight children and adolescents. N Eng J Med 2005;19:2100-9.

3. Ramachandran A, Snehalatha C, Vinitha R, Thayyil M, Kumar CK, Sheeba L, et al. Prevalence of overweight in urban Indian adolescent school children. Diabetes Res Clin Pract 2002;57:185-90.

4. Mc Donald A, Bradshaw RA, Fontes F, Mendoza EA, Motta JA, Cumbrera A, et al. Prevalence of obesity in panama: Some risk factors and associated diseases. BMC Public Health 2015; 15:1075.

5. Mehari A, Afreen S, Ngwa J, Setse R, Thomas AN, Poddar V, et al. Obesity and pulmonary function in African Americans. PLoS One 2015;10:e140610.

6. Zhang YX, Zhao JS, Chu ZH, Zhou JY. Prevalence of elevated blood pressure is associated with the increasing prevalence of obesity among children and adolescents in Shandong, china. Int J Cardiol 2015;201:150-1.

7. Flegal KM, Kit BK, Orpana H, Graubard BI. Association of all-cause mortality with overweight and obesity using standard body mass index categories: A systematic review and meta-analysis. JAMA 2013;309:71- 82.

8. Wang H, Zhai F. Programme and policy options for preventing obesity in china. Obes Rev 2013;14 Suppl 2:134-40.

9. Addo PN, Nyarko KM, Sackey SO, Akweongo P, Sarfo B. Prevalence of obesity and overweight and associated factors among financial institution workers in Accra metropolis, Ghana: A cross sectional study. BMC Res Notes 2015;8:599.

10. Lifshitz F, Lifshitz JZ. Globesity: The root causes of the obesity epidemic in the USA and now worldwide. Pediatr Endocrinol Rev 2014;12:17-34.

11. Obesity: Preventing and Managing the Global Epidemic. Report of a WHO consultation. World Health Organ Tech Rep Ser 2000;894:1$12,1-253$

12. World Health Organization (WHO). World Health Statistics 2012. Geneva: WHO; 2012. Available from: http://www.who. Int/gho/ publications/world health statistics/EN WHS2012 Full.pdf. [Last accessed on 2012 Nov 28].

13. Gogoi A, Neog B, Gogai N. Dubious anti- obesity agent HCA from Gracinia: A systematic review. Int J Pharm Pharm Sci 2015;7:1-8.

14. James WPT, Jackson-Leach R, Ni Mhurchu C, Kalamara E, Shayeghi M, Rigby NJ, et al. Overweight and obesity (high body mass index). In: Ezzati M, Lopez AD, Rodgers A, Murray CJL, editors. Comparative Quantification of Health Risks: Global and Regional Burden of Disease Attributable to Selected Major Risk Factors. Vol. I. Geneva: World Health Organization; 2004. p. 497-596.

15. World Health Organization (WHO). Global Health Risks: Mortality and Burden of Disease Attributable to Selected Major Risks. Geneva: Switzerland, WHO; 2009. Available from: http://www.who.int/ healthinfo/global burden disease/GlobalHealthRisks report full.pdf. 
[Last accessed on 2014 Feb 03].

16. Mohan V, Deepa R. Obesity and abdominal obesity in Asian Indians. Indian J Med Res 2006;123:593-1.

17. Shivanna R, Parizadeh H, Rajkumar GH. In vitro anti-obesity effect of macrolichens hetrodermia leucomelos and ramalina celastri by pancreatic lipase inhibitory assay. Int J Pharm Pharm Sci 2017;9:???

18. Deepa M, Farooq S, Deepa R, Manjula D, Mohan V. Prevalence and significance of generalized and central body obesity in an urban Asian Indian population in Chennai, India (CURES: 47). Eur J Clin Nutr 2009;63:259-67.

19. Misra A, Khurana L. Obesity and the metabolic syndrome in developing countries. J Clin Endocrinol Metab 2008;93:S9-30.

20. Mohan V, Mathur P, Deepa R, Deepa M, Shukla DK, Mennon GR, et al. Urban rural differences in prevalence of self- reported diabetes in IndiaWHO-ICMR Indian NCD risk factor surveillance. Diabetes Res Clin Pract 2008; 80: 159-168.

21. Chadha SL, Gopinath N, Shekhawat S. Urban-rural differences in the prevalence of coronary heart disease and its risk factors in Delhi. Bull World Health Organ 1997;75:31-8.

22. Sidhu S, Kaur A, Prabhjot. Prevalence of overweight and obesity among urban and rural adult females of Punjab. Anthropol Anz 2005;63:341-5.

23. International Institute for Population Sciences (IIPS) and ORC Macro. National Family Health Survey (NFHS-2); 1998-1999: India. Mumbai: IIPS. Available from: http://www.nfhsindia.org/data/hr/hrchap7.pdf. [Last accessed on $2008 \mathrm{Feb}$ ]

24. Venkatramana P, Reddy PC. Association of overall and abdominal obesity with coronary heart disease risk factors: Comparison between urban and rural Indian men. Asia Pac J Clin Nutr 2002;11:66-71. Yadav K, Krishnam A. Obesity reviews urbanization and its impact on obesity. Int Assoc Study of Obesity 2008;9:400-8

25. International Agency for Research on Cancer. Fruits and vegetables. International Agency for Research on Cancer. Handbooks of Cancer Prevention. Vol. 8. Lyon: International Agency for Research on Cancer Press and World Health Organization; 2002

26. WHO. World Health Report 2002: Reducing Risks, Promoting Healthy Life. Geneva: WHO; 2002.

27. Nestle M, Jacobson MF. Halting the obesity epidemic: A public health policy approach. Public Health Reports 2000;115:12-24.

28. Monteiro CA, Moura EC, Conde WL, Popkin BM. Socio economic status and obesity in adult populations of developing countries: A review. Bull World Health Organ 2004;82:940-6.

29. Popkin BM, Gordon-Larsen P. The nutrition transition: Worldwide obesity dynamics and their determinants. Int J Obesity 2004;28:S2-9.

30. Popkin BM. The shift in stages of the nutrition transition in the developing world differs from past experiences. Public Health Nutr 2002;5:205-14.

31. WHO. Preventing Chronic Disease. Vital Investment. Geneva: WHO; 2005.

32. National Commission on Macroeconomics and Health. Report of the National Commission on Macroeconomics and Health. New Delhi: Ministry of Health and. Family Welfare Government of India: Section I-Investing in Health for Economic Development; 2005. p. 31. 